\title{
Exploring the suitability and acceptability of peer support for older veterans
}

Karen Burnell, Adrian Needs, Kim Gordon

\begin{abstract}
Purpose: Informal social support is often sought by veterans to support reminiscence or cope with traumatic memories. However, it can also encourage unhelpful ways of coping, such as avoidance, or may be absent altogether. This project borrowed from the growing peer support literature to explore the suitability of peer support services to enhance wellbeing for older veterans, when naturally occurring support is absent or unhelpful.

Methodological approach: This was a sequentially staged research programme involving a scoping review of current practice and evidence, and a consultation with veterans. In total, 10 veterans (nine male, 1 female) took part in the consultation $(M=66$ years $)$.

Findings: Peer support was considered a suitable, particularly in addressing loneliness and social isolation. There was an understandable concern regarding its use with more complex issues such as trauma. An added issue was the implicit assumption that this consultation concerned transition; supporting younger veteran as they move from military to civilian life. This mirrored the focus of current UK policy and affected the focus of the consultation. Issues were also raised around sustainability of services more broadly.
\end{abstract}

Social implications: Peer support is appropriate in supporting older veterans, but must be implemented in a sustainable way. Raising awareness of the needs of older veterans in older adult services is an important implication for service development and delivery.

Originality: There is a considerable lack of research concerning older veterans, particularly concerning their formal and informal social support needs. This paper addresses the current gap in the literature.

Keywords: Veterans, older adults, peer support, social support, befriending, loneliness, , social interventions 


\section{Exploring the suitability and acceptability of peer support for older veterans}

\section{Introduction}

The mental health and wellbeing of formerly serving military personnel (known here as veterans) has been a focus of policy and research for some time. While most leave the forces in good physical and mental health, there are others for whom the change in circumstance is not as positive, contributing to posttraumatic stress disorder (PTSD), depression, and anxiety, and alcohol misuse, which require formal intervention (e.g. Mental Health Foundation, 2013). Others may never develop clinical disorders, but live with subclinical symptoms that impact on their daily lives (Litz, Steenkamp and Nash, 2014). Particularly salient here is that some function successfully and without any symptoms for many years, but may experience stress related symptoms in later life (e.g. Bender, 1997; Davison et al., 2006; Elder and Clipp, 1989; Hunt and Robbins, 2001), perhaps due to changes in cognitive function, physical health, and social support (Baltes and Lang, 1997; Floyd, Rice and Black, 2002), or the natural desire to reminisce.

This focus on emergence or later-life re-experiencing is vital, yet masks a more subtle issue; understanding the impact of service from a lifespan perspective and the need for sustained meaningful social relationships (Settersten and Patterson, 2006; Spiro and Settersten, 2012). From a developmental perspective, service experience is most likely to occur during late adolescence and early adulthood and therefore might be seen as an intrinsically meaningful and influential life stage. If service continues into middle and later adulthood, then these experiences comprise the majority of one's life experiences. Taken a step further, this has implications for the life review process: the drive to revisit memories in later life (Butler, 1963; Erikson, 1994). The life review process occurs in later life and involves reflection upon the life story, through reminiscence (i.e. Wong and Watt, 1991), which serves to maintain identity and self-esteem (Coleman, 1999) and has been found to be valuable for veterans in 
coping with traumatic memories (i.e. Shaw \& Westwood, 2002) and as a pleasurable activity (i.e. Sixsmith, Sixsmith, Callender and Corr, 2014). .

Naturally occurring comradeship would seem to be the most obvious form of support. Indeed, the importance of comradeship is borne out in the literature with social connectedness and participation (Choi, DiNitto, \& Marti, 2016), and belonging (Barron, Davies, \& Wiggins 2008) having an impact on perceived health and wellbeing. Further, Yang and Burr (2015) recently determined that even in later life, veterans' subjective wellbeing can be moderated by social support. However, while previous research suggested comradeship to be essential in helping veterans cope with experiences (Hunt and Robbins, 2001), further exploration determined that there can be occasions where avoidance or noncommunication takes place between veterans, resulting in ways of coping that might be maladaptive (Burnell, Coleman and Hunt, 2006, 2010). Alternatively, these friendships may no longer be available to older veterans. Due to natural changes during life, veterans may lose family and comrades who may have helped them cope (Hunt and Robbins, 2001), or there may be a natural reduction in the size of social networks (Isaacowitz, Smith and Carstensen, 2003). Difficulties may emerge in later life around retirement when, once again, social networks may be lost or reduced (Allen, 2008). In addition, for older populations generally, there are increased concerns around social isolation and loneliness (Department of Health 1999, 2001), which means that older people may not have anyone to share important experiences with (Cook and O'Donnell, 2005) or the means to attend relevant groups. As such, there may be lost opportunities for identity maintenance through reminiscence or coping with difficult memories.

Being a veteran may pose an additional risk since changes in the nature of war and conflict, and reduction of personnel in the British Armed Forces, may see the veteran population become increasingly dispersed and invisible. The recent Household Survey conducted by The Royal British Legion (TRBL, 2014) found that the British veteran population is currently elderly and declining in size. This may become increasingly so if we pace forward to those who have served in less well known 
conflicts post- World War II and what the needs of these small cohorts of veterans may be as they age. It is not that exposure to stressful or traumatic events is exclusive to service life, but there is an increased likelihood to exposure and a sense of comradeship and cohesion that perhaps presents different types of need in later life.

For reasons associated with developmental tasks, such as the desire to reminisce, as well as working through or coping with difficult memories, those who have served at some point in their lives may benefit from informal, but organised, low intensity peer support, naturally occurring support is either absent or not appropriate. Peer support is defined here as support from a non-professional who has experienced similar life events or challenges to the person they are supporting (Dennis, 2003), and with whom there is shared understanding and trust. Peer supporters provide companionship (as with befriending), a listening ear, and can signpost if necessary. The objective of the current study was to explore the suitability and acceptability of peer support for older veterans. Older veterans are defined here as those 55 years and over, which is in line with UK government definitions, but the implicit focus was on the older and oldest old veterans. To achieve this, a scoping exercise concerning current UK practice and the international evidence for peer support for older veterans was carried out ahead of the consultation.

\section{Scoping current practice in the UK}

Although a great number of community-based support interventions exist for veterans in the United Kingdom (UK) their content and impact is not well known. Fifty organisations were identified that provide informal support, with 17 offering a form of peer support. Consistent with reviews in other contexts (e.g. Creamer et al., 2012), there was considerable variation in the nature of provision. Of the 50 organisations, the vast majority used the terms peer support to describe informal and unstructured support. That is, veterans took the opportunity to talk to one another between therapy sessions and the support was not planned or guided. It was also used to describe mutual group support. In some cases there was no facilitator, in others a member of the group was nominated as a facilitator. In most cases, 
there was an absence of a more experienced, trained peer. Peers was also used to describe those who were not health professionals but were not formerly serving either; lay supporters in other contexts. Of the 17, two appeared to be peer support models as defined in the current research. One involved a drop in service where peers provided a listening ear and signposted onto other services. The other involved a goal directed service in which formerly serving personnel were matched with a trained peer or lay supporter (Cronin, 2013).

\section{Scoping the evidence base}

There is also limited academic and clinical research evaluating peer support for veterans of any age group or gender, but particularly those who are older. Evidence from other health contexts suggests that low intensity peer support services are viable and systematic reviews concerning the effectiveness of peer support suggest that there is some evidence that they have beneficial effects. For instance, Pitt et al (2013) reviewed the impact of consumer-providers in mental health services provision and found that the impact on quality of life for those supported by a peer was equal to that of a person supported by a professional. In addition, there might be other benefits such as a reduction in boundaries in accessing care.

In terms of the case of peer support for veteran populations, Bird (2015) highlighted a number of programmes focusing on the role of peer support to enhance adherence to mental health programmes, destigmatise mental health issues, and to decrease depressive symptoms. However, the target populations were either currently serving personnel, or those transitioning to civilian life while still in younger adulthood. The scoping review carried out as part of the current research explored the evidence for peer support for formerly serving veteran populations (reference removed). Four peer support models were identified, but none were specifically for older. One of the models, Shoulder to Shoulder, was based in the UK (Cronin, 2013), with the other three based in the United States of America (USA); Vet-to-Vet (Barber, Rosenheck, Armstrong and Resnick, 2008; Eisen et al., 2012; Goldberg and Resnick, 2010; Resnick, Armstrong, Sperrazza, Harkness, Resnick and Rosenheck, 
2004; Resnick and Rosenheck, 2010), Buddy-to-Buddy (Greden, et al., 2010), and Veterans Administration (VA) Little Brother/Sister programme (Jain, McLean and Rosen, 2012). The interventions also focused on acute conditions, as opposed to enhancing wellbeing and reducing isolation, or focused on enablement by providing practical support. It remains essential that the concept of low intensity peer support for older veterans is explored, particularly in the context of gerontological theory.

\section{Method}

The aim of the veteran consultation was to explore veterans' experiences of previous help seeking behaviours, perceptions of peer support, and to explore potential components of a peer support service. This was achieved through consultation with veterans, who were involved as stakeholders. Two levels of involvement were utilised: First, consultation allowed for the exploratory, developmental aspect of the research (Minogue, 2009); second, a formerly serving member of the community, who had used relevant services, worked as part of the research team in a collaborative capacity (Rose, 2009).

Veterans aged 55 years and over were invited via local gatekeepers, such as Engage (the School of Health Sciences and Social Work's public involvement panel), the University of Portsmouth Ageing Network (UPAN), and various veteran organisations across Hampshire, as well as internet communities, such as the ARmy Rumour SErvice (ARRSE). In total, 10 veterans (9 male and one female) were involved in the consultation with one just below 55 years of age (Range $=54-78 ; M=$ 66). Length of service ranged from four and a half years to 38 years $(M=20.6$ years), and all services were represented, with six veterans having served in the Royal Navy, two in the British Army, one in the Royal Air Force (RAF), and one in both the Royal Air Force and British Army. All provided valid informed consent and the study had received favourable opinion from the Science Faculty Ethics Committee.

The consultation comprised a number of elements including a questionnaire, which was used as way to introduce the topic and stimulate thinking, and a series of focus group discussions. The first 
round of focus group discussions focused predominantly on perceptions, suitability, and feasibility of peer support for older veterans. The veterans were split into two groups, with two facilitators per group. A fifth team member moved between groups to get a sense of differences and similarities between groups. A semi-structured focus group schedule was used and all discussions were audio recorded and later transcribed. After the focus group discussions, the whole group reconvened and the facilitators fed back the main points from the focus group discussion, and all attendees were invited to comment. The second focus group discussion took place, with the two groups focusing on a different topic area. The first group discussed the role of the peer supporter, delivery (e.g. online or in person), format of the service (e.g. one-to-one or group), as well as issues around length of engagement and peer supporter training. The second group discussed essential characteristics of peer supporters, as well as the types of support provided to those using the service and also those providing the service. A large group discussion then took place, allowing all attendees to comment on all the points raised. After a note of thanks, the consultation was brought to a close.

\section{Results}

The group discussions were analysed using inductive thematic analysis (Joffe and Yardley, 2004) at both the manifest and latent levels, and managed through NVivo 10. Descriptive statistics were carried out on the questionnaire data, with responses to the question items summarised as medians, and are presented alongside the findings of the thematic analysis to add context. Three themes emerged from the focus group discussions. These were; perceptions of peer support, developing a peer support service, and transition versus later life wellbeing.

\section{Perceptions of Peer Support}

Some participants felt strongly that peer support specifically for veterans by veterans is essential, because being part of the Armed Forces contributed to a sense of identity that was difficult to leave behind post service:

I think the trouble is that once you kick off into the armed services, whether you like it or not it becomes engrained in you... (participant 1) 
As such, there was a great need for veterans to support veterans due to the power of common ground, shared identity, and mutual understanding:

So I think myself that if you have a befriender service, I mean I know myself that if I had particular problems, if I rung up and I got an ex-matelot or an ex-marine or somebody to come and see me I think I'd probably be quite pleased about it because I'd think, well, okay, this person has been through the service like I have, they'll think like me and they'll understand like me; so I think it is important to have a link... (participant 1)

Also of importance were themes around trust and understanding. There was recognition that a veteran's needs may be no different to a civilian of the same age, but that with shared experiences comes understanding and a willingness to open up:

We only tend to talk amongst our own peers, we don't talk about our circumstances, our problems, with outsiders, because they don't understand (participant 2)

Not all stakeholders felt this way, however. A minority felt that there should be a conscious effort to leave behind a veteran identity. Implicit in this idea is that peer support should support transition:

They're not gonna be veterans, hopefully, for the rest of their lives, are they, you know, eventually they're gonna become civilians (participant 3)

Organised peer support was also seen to be important in the context of geographical dispersion of veterans, absence of community, and subsequent absence of informal support. According to following quote, the potential practical support provided by existing organisations can be confusing and the informal social support can be exclusive. The result is an absence of the often assumed informal support provided by comrades:

I think first of all most [organisations] will say, well, okay, what sort of help do you need, and they've said, well, you know, a bit of financial; they'll slap a form down and the chap will look through the thing and be, no, no, no, forget it, you know, that's just far too complex; well, okay, how can we help, well, I'd like to mix with some of the...okay, come down to our local social club. So you go down the local social club and there's a few people down there, they're a bit cliquey, another ex-serviceman comes in the door and perhaps because he's not part of the regular drinking group he'll stay there two or three nights and then he'll say enough is enough (participant 1) 
While peer support was seen as being important, barriers were also discussed, such as the large number of organisations already providing support for formerly serving personnel:

And there's so many different groups, and they can all provide different things, and there's no one size to fit all, and it's knowing where to go for the particular fit (participant 4)

Associated with this, there were concerns about establishing more organisations in an already flooded market place. As one veteran said: '[saying] well, let's add another one to the mix is necessarily the smart thing to do' (participant 5). Despite this, others felt that there was a place for peer support:

It's a brilliant concept, as long as it doesn't actually parallel or copy what's already available. It must enhance it, it must be an add-on, it must enhance what's already available (participant 4)

Another barrier was issues around stigma, particularly for older veterans for whom avoidance was seen as a natural coping strategy:

The problem with that group that you specified is actually getting them to say, well, I've got a problem and actually saying I need to do something about it. Because going back to what I used to in SSAFA (Soldiers, Sailors, Airmen, and Families Association) earlier in my volunteering, they don't talk about these things, they just don't talk about it (participant 6)

While peer support was seen as appropriate, veterans raised important boundaries. These centred on what peer support should not be. Very strongly the message was that it should not attempt to be a formal treatment for mental health problems:

I was aware of the fact that I was ill and I needed professional help. I didn't need to sit down with [a peer], I needed to sit down with a professional and get professional help, which I did and that all worked fine. But sitting, you know, chatting it through with somebody who could conceivably have done more damage is not what I needed (participant 5)

Developing the Service

Themes centred on the aim of the service, content of the service, and concerns around governance and best practice. In particular, discussions focused on understanding the type of contact between veteran and peer in terms of its nature, format, frequency, and duration. In discussions concerning the nature of contact, emotional support and signposting were the most prevalent themes. The following quote 
captures the complementary nature of emotional support and signposting, but also highlighted the informal, personable, nature of peer support:

[it's a bit like the] discussion you have with your mate down the pub, you know, at one level, just being able to talk through the strains and say I've been having a really crap week this has been happening. I think because people don't have anybody else to talk to it's a confidante...but out of that conversation might come things like well actually you really need to go and see the housing people or British legion can probably help you if this is an issue or have you not been to SSAFA? (participant 7)

Peer support was also seen as a way of preventing more complex problems developing, in a sense 'before the problem starts' (participant 7). The veterans also discussed the format of peer support in terms of whether support should be offered face to face, remotely, in groups or one on one. Although one to one support proved slightly more popular than group support, there was an acknowledgement that a range of formats would be required:

Well you need to be able to offer all of it because some people are not group people but they need to know it's there if they want it (participant 4)

Very practically, participant four also highlighted that the format and provision of the service would 'depend upon resources'. An advantage of group meetings was that group activities could also be included to promote further communication and peer support:

Some people might like to do groups because we haven't really talked about will they want to have some sort of small group things as well just to discuss experiences...(participant 7)

Whether as part of a group or one to one, all stakeholders were clear that support should be provided face to face, and that remote support using the telephone or internet was not suitable for this group.

In terms of frequency and duration of contact, stakeholders felt that contact should be provided on a needs basis, and their main concern was about careful management of the duration of the relationship to avoid creating dependency. Speaking from experience of his professional role supporting veterans, participant eight suggested: 
I've seen [people] that [sic] have had really long-term support for a number of years; but the majority it's months. And it could be two months, it could be six, nine months (participant 8)

To tackle the issue of dependency, another stakeholder spoke of the befriending service his organisation provides, which carefully manages the frequency and duration of support:

Have just six visits by one of our volunteers to that person, because anything more than that and they tend to become reliant upon that one person; so we do a routine where the person, the volunteer, arranges to go on six times, and then we'll get another one of the befrienders to go in and do another six (participant 9)

In developing the service, veterans also spoke of the importance of personalising the service to suit the needs of the person requesting support. Three subthemes emerged; these were tailoring, matching, and opportunity to involve family members. There was a clear indication that needs will vary, and the service would need to be tailored to be as effective as possible:

Each person's circumstances is individual and it needs to be tailor made to the specific needs of that person; you have to identify (participant 10)

Matching related to the how to place peers and service users together to best create supportive relationships. In this context, rank was seen as being unimportant, while having similar service experience, particularly experience of the same branch of the services, seemed fundamental:

Speaking with somebody who's ex-Navy would be easier, because a lot of the slang that you use is the same. But talking to, some of the things that my brother-in-law speaks about goes straight over. I just can't identify with, I don't have that with... and that is some of the terms he uses. And you know, they're foreign to me (participant 10)

The veterans also emphasised the importance of governance and best practice. This included the selection of volunteers, contracts or ground rules (participant 7), confidentiality, safety, training, monitoring of peer support pairs or groups, and support for the volunteers themselves. These concerns lead to the conclusion that a role must be created to support the service, such as a coordinator, to provide light touch (participant 1) governance:

So does that need something or someone to be able to, sort of, monitor the situation, some means or methods, without being intrusive (participant 1) 
The selection of the volunteer was also seen as a critical aspect of a coordinator's role to 'suss out the motives (participant 4) and to ensure that only the most suitable candidate offer help to others:

the last thing that I want is some bloody do-gooder coming round and this sort of thing. But that doesn't mean to say I'm not prepared to accept help from people. But there are some people who want to come and take over. And so I think possibly there needs to be a little bit of checking on suitability, you know... (participant 10)

Another role for the coordinator would be to support the volunteers was important, not only to support them in what may be emotionally burdensome peer matches, but also to support working within the boundaries of practice:

Yeah, I think that's really important because actually you may hear things or you may...you don't necessarily want to break any confidence issues but you may hear things and say what would I do with that situation if somebody was admitting to, I don't know, illegal drug abuse or battering their wife or all sorts...it could be almost anything or it could be that they've had an accident and they haven't done anything about it. Where do my boundaries lie? (participant 7)

Given the need for a coordinator, veterans spontaneously discussed the types of organisations that could host a peer support service, and provide much needed infrastructure. There was the suggestion of established veteran organisations such as The Royal British Legion who could provide a 'sort of a foundation that this sort of thing could be built on' (participant 10). Others cautioned around the 'suspicion of officialdom' (participant 4). An alternative was suggested in which peers could be suitably matched, but the organisation iself need not be a veteran organisation:

If things like the befriending scheme that you're [participant 9 is] involved in - and it sounds to me like a brilliant idea-are in place, they have a universal appeal whether you're ex-service, whether you're not ex-service, whether you're disabled or if you're not disabled, and you have those requirements, that kind of scheme meets that; so therefore those sort of services are not required specifically for the ex-service community (participant 5)

\section{Transition versus Wellbeing}

Within one group, tensions arose through the consultation day about the need for a veteran specific peer support service. Moreover, in all group discussion there was an absence of focus on the deeper issues of peer support for older veterans or, indeed, issues around practicalities for supporting older 
veterans, such as accessibility of services. Subsequent interrogation of the data revealed assumptions had been made throughout the day, which influenced the discussions. Two competing themes emerged from the data: transitions vs. wellbeing.

A number of the veterans' discussions focused on the purpose of peer support 'to decommission and individualise veterans' (participant 4). For others, the latent theme of transition emerged in talk about the needs of younger veterans:

It's different from 20, 30 years ago, you're dealing with hardened individuals now; they need a different type of service, now they need, some of them - not all of them, again - some of them just need a bit of hand holding just to integrate, literally integrate, back into society; because they've been in the hard end for years some of them (participant 6)

Indeed, different types of need were discussed for those now leaving the service, rather than the needs of veterans as they reach later life:

My thoughts on...given some thought was there are two types of people, ones that are leaving at the end of their period which would have been planned in their contract and others that are leaving possibly unexpected (participant 6)

These issues, so at the forefront of some of the stakeholders' minds, perhaps explain why some felt the research programme had not identified a real need or 'gap in the market' (participant 5), and concerns around an already flooded market place. Despite this, the needs of older veterans were a priority for other stakeholders, who spoke without prompting about issues of loneliness and isolation in later life:

One of the things I'm reading in the papers now, that one of the greatest problems amongst elderly people is loneliness; and I think we've got to start thinking about loneliness, especially amongst ex-service personnel. And I think basically what we've got to look at, I don't think it's a case of pouring money on there, I don't think it's a case of providing clubs because I don't think they always work; I think it's somehow trying to find a sort of service that can have volunteers who can spend time to perhaps once a week either lift the telephone and have an hour's chat with an ex buddy or something, or somebody who's prepared to visit an ex-serviceman who's struggling a bit, do a little bit of shopping for him, something like that (participant 1)

This implicit focus on younger veterans by the participants is perhaps also mirrored by the current focus of research and policy, particularly in the UK. 


\section{Discussion}

According to the literature, military service appears to have an impact on veterans' wellbeing in later life. When considered alongside gerontological theory concerning the role of reminiscence and life review in maintaining identity and, in turn, wellbeing, there is a role for the provision of support where naturally occurring social support is absent or unsuitable. The current study explored the suitability and acceptability of peer support interventions for older veterans. Peer support was seen as a suitable intervention to provide informal but effective service provision, particularly in the context of addressing issues around loneliness and isolation in later life. This issue is of current concern for older adults generally, but may be exacerbated for older veterans.

The exploration of current service provision and evidence highlighted an absence of peer support for older veterans in both practice and theory. Much of the research focused on younger veterans or acute mental health issues. While results of the consultation demonstrated the feasibility and suitability of peer support for the old-old and oldest old veterans in reducing isolation, concerns were raised around duplication of services. Further exploration of the findings indicated that there may have been two areas of concern for the veterans involved in this study: peer support for transition in earlier life and peer support for wellbeing in later life. While some of the attendees were concerned with the latter, others were concerned with the former, which may have affected the findings. Interestingly, this parallels the current concern of research and policy with a focus on the transition of younger veterans (Forces in Mind Trust, 2013; Kelly, Howe-Barksdale and Gitelson, 2011), while the needs of older veterans arguably remain unaddressed or even unacknowledged (Settersen and Patterson, 2006; Spiro and Settersen, 2012).

The veterans cautioned against peers providing formal mental health interventions, which was in contrast to the focus of the research reviewed as part of the scoping exercise. It is, however, in line with the theory concerning peer support (Dennis, 2003), lessons from research with other populations (e.g. carers; Burnell et al., 2015), as well as the general purpose of befriending interventions (Cattan, 
White, Bond and Learmouth, 2005), which is to provide low intensity support and signposting. It also highlights the importance of formal training and supervision for peers.

The elements of peer support highlighted by the veterans during the consultation were inkeeping with much of the literature concerning peer support used in other settings. That is, the role of peer support to serve as providing a listening ear and the potential effectiveness of peer support due to shared experiences. In addition, it is important to note that, while older veterans may benefit from support provided by others who have served, the format of peer support proposed here are coherent with the content, format, and infrastructure of befriending schemes that exist across sectors. The suggestion in this study to build peer support into social group activities may also be a fruitful option moving forward (Cattan et al., 2005).

The implication here is that existing befriending services could be adapted to become peer support services, simply by matching veterans with veterans. This was echoed by further consultation with service providers from local services, who acknowledged that awareness of the needs of older veterans should be made more explicit to service providers of older adult services across sectors. This would create sustainable services moving forward against a back drop of a decreasing older veteran population, but which recognise the potential impact of service experience in later life. An additional advantage is that, to access these services, one would not have identify oneself as a veteran, which is a possible barrier to service uptake. It is preferable that existing services in trusted organisations are adapted rather than establishing new initiatives or organisations.

It might be argued that the veterans who attended the consultation fitted the profile of service provider more than service user, and were involved in services implicitly linked to aiding transition. The veterans who spoke of issues around loneliness and isolation were involved in befriending services, which might have given them a different frame of reference. Of course, interventions can and should be put in place to support younger veterans as they transition to civilian life. Indeed, if we take a life course perspective (George, 1996), transitioning successfully in earlier life may alleviate some 
of the difficulties in reconciling change and maintaining identity into later life. While there is a pressing need for earlier life reconciliation, it cannot be that all veterans will get such timely intervention. The literature to date suggests numerous reasons as to why this may not occur for younger veterans, and so the logical conclusion is that need will present in later life. In addition, current transition programmes capture those who are currently leaving the military, leaving cohorts who did not have these same opportunities. Consequently, there may be generations of veterans who may require support in later life, particularly when the natural activities of life review and reminisce trigger this search for meaning. Engagement with a group more generally is associated with more healthy cognitive functioning in older adults and, consistent with the present findings, this can be facilitated by a sense of shared identity (Haslam, Cruwy and Haslam, 2014). It is important to increase the clarity concerning processes and practicalities around the target service users and to engage this population to a greater extent through further development and evaluation of peer support services.

As Settersten argued in 2006 and later in 2012, as a research community we need to focus more on acknowledging and understanding the impact of service experience in later life. The impact of this would be seen in the development of much needed services for older veterans, who seem to be a forgotten cohort, even within the formerly serving community.

\section{References}

Allen, J. (2008), Older people and wellbeing. London: Institute for Public Policy Research. Retrieved from:http://www.ippr.org/files/images/media/files/publication/2011/05/older_people_and_well being_1651.pdf?noredirect=1

Baltes, M. M. and Lang, F. R. (1997), "Everyday functioning and successful aging: The impact of resources", Psychology and Aging, Vol. 12, pp. 433-443. doi:10.1037/0882-7974.12.3.433

Barber, J. A., Rosenheck, R. A., Armstrong, M., and Resnick, S. G. (2008), "Monitoring the 
dissemination of peer support in the VA Healthcare System", Community Mental Health Journal, 44, pp. 433-441. doi: 10.1007/s10597-008-9146-7

Barron, D. S., Davies, S. P., \& Wiggins, R. D. (2008). Social integration, a sense of belonging and the Cenotaph Service: Old soldiers reminiscence about Remembrance. Aging \& Mental Health, 12(4), 509-516. doi:10.1080/13607860802224628

Bender, M. P. (1997), "Bitter harvest: The implications of continuing war-related stress on reminiscence theory and practice", Ageing and Society, Vol. 17, pp. 337-348. Retrieved from http://journals.cambridge.org/action/displayAbstract?fromPage=online\&aid=32853\&fileId=S0 144686X9700648X

Bird, K. (2015), "Peer Outdoor Support Therapy (POST) for Australian Contemporary Veterans: A Review of the Literature", Journal of Military and Veterans' Health, Vol. 22, pp. 4-23. Retrieved from: http://jmvh.org/article/peer-outdoor-support-therapy-post-for-australian-contemporaryveterans-a-review-of-the-literature/

Burnell, K. J., Coleman, P. G. and Hunt, N. (2006), "Falklands War veterans' perceptions of social support and the reconciliation of traumatic memories", Aging \& Mental Health, Vol. 10, pp. 282289. doi:10.1080/13607860500409385

Burnell, K. J., Coleman, P. G. and Hunt, N. (2010), "Coping with traumatic memories: Second World War veterans' experiences of social support in relation to the narrative coherence of war memories", Ageing and Society, Vol. 30, 57-78. doi:10.1017/S0144686X0999016X

Burnell, K. J., Selwood, A., Sullivan, T., Charlesworth, G. M., Poland, F. and Orrell, M. (2015), "Involving service users in the development of the Support at Home: Interventions to Enhance Life in Dementia Carer Supporter Programme for family carers of people with dementia", Health Expectations, Vol. 18, pp. 95-110. doi: 10.1111/hex.12012 
Butler, R. (1963), "The life review: An interpretation of reminiscences in the aged", Psychiatry, Vol. 26, pp. 65-76. doi:10.1521/00332747.1963.11023339

Cattan, M., White, M., Bond, J. and Learmouth, A. (2005), "Preventing social isolation and loneliness among older people: A systematic review of health promotion activities", Ageing and Society, Vol. 25, 41-67. doi:10.1017/S0144686X04002594

Choi, N. G., DiNitto, D. M., \& Marti, C. N. (2016). Social participation and self-rated health among older male veterans and non-veterans. Geriatrics \& Gerontology International, 16, 920-927. doi: 10.1111/ggi.12577

Coleman, P. G. (1999), "Creating a life story: The task of reconciliation", The Gerontologist, Vol. 39, pp. 133-139. doi: 10.1093/geront/39.2.133

Cook, J. M. and O’Donnell, C. (2005), "Assessment and psychological treatment of Posttraumatic Stress Disorder in older adults", Journal of Geriatric Psychiatry and Neurology, Vol. 18, pp. 6171. doi: $10.1177 / 0891988705276052$

Creamer, C. M., Varker, T., Bisson, J., Darte, K., Greenberg, N., Lau, W. et al. (2012), "Guidelines for peer support in high-risk organizations: An international consensus study using the Delphi Method", Journal of Traumatic Stress, Vol. 25, 134-141. doi:10.1002/jts.21685

Cronin, O. (2013), Final evaluation of the Timebank Shoulder to Shoulder Project (London and Birmingham). Retrieved from Orla Cronin Research / TimeBank: http://timebank.org.uk/sites/timebank.org.uk/files/S2S\%20evaluation\%20June\%2025,\%20201 3.pdf

Davison, E. H., Pless, A. P., Gugliucci, M. R., King, L. A., King, D. W., Salgado, D. M., et al. (2006), "Late-life emergence of early-life trauma: The phenomenon of late-onset stress symptomatology 
among aging combat veterans", Research on Aging, Vol. 28, 84-114. doi: $10.1177 / 0164027505281560$

Dennis, C. L. (2003), "Peer support within a health care context: A concept analysis". International Journal of Nursing Studies, Vol. 40, pp. 321-332. doi:10.1016/S0020-7489(02)00092-5

Department of Health. (1999). Saving Lives : Our Healthier Nation, Stationery Office, London.

Department of Health. (2001), National Service Framework for Older People, Author, London.

Eisen, S. V., Schultz, M. R., Mueller, L. N., Degenhart, C., Clark, J. A., Resnick, S. G. et al. (2012), "Outcome of a randomized study of a mental health peer education and support group in the VA", Psychiatric Services, Vol. 63, pp. 1243-1246. . doi: 10.1176/appi.ps.201100348

Elder, G. H. and Clipp, E. C. (1989), "Combat experience and emotional health: Impairment and resilience in later life", Journal of Personality, Vol. 57, pp. 311-341. doi:10.1111/j.14676494.1989.tb00485.x

Erikson, E. H. (1994), Identity and the Life Cycle. (2 ${ }^{\text {nd }}$ ed.), W. W. Norton \& Company, New York, NY.

Floyd, M., Rice, J. and Black, S. R. (2002), "Recurrence of posttraumatic stress disorder in late life: A cognitive aging perspective", Journal of Clinical Geropsychology, Vol. 8, pp. 303-311. doi:10.1023/A:1019679307628

Forces in Mind Trust. (2013). The Transition Mapping Study: Understanding the Tranistion Process for Service Personnel Returning to Civilian Life, Author, London.

George, L. K. (1996), "Missing links: the case for a social psychology of the lifecourse", Gerontologist, Vol. 36, pp. 248-255. doi: 10.1093/geront/36.2.248 
Greden, J. F., Valenstein, M., Spinner, J., Blow, A., Gorman, L. A., Dalack, G. W., et al. (2010), "Buddy-to-Buddy, a citizen soldier peer support program to counteract stigma, PTSD, depression, and suicide", Annals of the New York Academy of Sciences, Vol. 1208, pp. 90-97. doi: 10.1111/j.1749-6632.2010.05719.x

Goldberg, R. W. and Resnick, S. G. (2010), "US Department of Veterans Affairs (VA) efforts to promote psychosocial rehabilitation and recovery". Psychiatric Rehabilitation Journal, Vol. 33, pp. 255-258. doi:10.2975/33.4.2010.255.258

Haslam, C., Cruwys, T. and Haslam, S.A. (2014), ""The we's have it": Evidence for the distinctive benefits of group engagement in enhancing cognitive health in aging", Social Science \& Medicine, Vol. 120, pp. 57- 66. doi:10.1016/j.socscimed.2014.08.037

Hunt, N. and Robbins, I. (2001), "World War II veterans, social support, and veterans' associations", Aging \& Mental Health, Vol. 5, pp. 175-182. doi:10.1080/13607860120038384

Isaacowitz, D. M., Smith, R. B. andCarstensen, L. L. (2003), "Socioemotional selectivity and mental health among trauma survivors in old age". Ageing International, Vol. 28, pp. 181-199. doi: $10.1007 / \mathrm{s} 12126-003-1023-7$

Jain, S., McLean, C. and Rosen, C. S. (2012), "Is there a role for peer support delivered interventions in the treatment of veterans with post-traumatic stress disorder?", Military Medicine, Vol. 177, pp. 481-483. Retrieved from: http://publications.amsus.org/doi/pdf/10.7205/MILMED-D-1100401

Joffe, H. and Yardley, L. (2004), "Content and thematic analysis", Marks, D. and Yardley, F. (Eds.), Research Methods for Clinical and Health Psychology, Sage, London, pp. 56-68.

Kelly, D.C., Howe-Barksdale, S. and Gitelson, D. (2011), Treating Young Veterans. Promoting Resilience through Practice and Advocacy, Springer Publishing Company, New York, NY. 
Litz, B. T., Steenkamp, M. M. and Nashy, W. P. (2014), "Resilience and recovery in the military", in Zoellner, L. A. and Zoellner andFeeny, N. C. (Eds.), Facilitating Resilience and Recovery following Trauma. Guildford Press, New York, NY.

Mental Health Foundation. (2013), The Mental Health of Serving and Ex-Service personnel: A Review of the Evidence and Perspectives of Key Stakeholders, Authors, London.

Minogue, V. (2009), "Consultation", in Wallcraft, J., Schrank, B. and Amering, M. (Eds.), Handbook of Service User Involvement in Mental Health Research, John Wiley \& Son, West Sussex, pp. 153-168.

Pitt, V., Lowe, D., Hill, S., Prictor, M., Hetrick, S. E., Ryan, R. and Berends L. (2013), "Consumerproviders of care for adult clients of statutory mental health services", Cochrane Database of Systematic Reviews, Issue 3. Art No.: CD004807. doi:10.1002/14651858.CD004807.pub2.

Resnick, S.G. Armstrong, M., Sperrazza, M., Harkness, L. and Rosenheck, R.A. (2004), "A model of consumer-provider partnership: Vet-to-Vet", Psychiatric Rehabilitation Journal, Vol. 28, pp. 185-187. doi.org/10.2975/28.2004.185.187

Resnick, S. G. and Rosenheck, R. A. (2010), "Who attends Vet-to-Vet? Predictors of attendance in mental health mutual support", Psychiatric Rehabilitation Journal, Vol. 33, pp. 262. doi:10.2975/33.4.2010.262.268

Rose, D. (2009), “Collaboration”, in Wallcraft, J. Schrank, B. and Amering, M. (Eds.), Handbook of Service User Involvement in Mental Health Research, John Wiley \& Sons, West Sussex, pp. 169-180.

Settersten, R. A., Jr. and Patterson, R. S. (2006), "Military service, life course, and aging: An introduction", Research on Aging, Vol. 28, pp. 5-11. doi:10.1177/0164027505281579 
Sixsmith, J., Sixsmith, A., Callender, M. and Corr, S. (2014), "Wartime experiences and their implications for the everyday lives of older people", Ageing and Society, Vol. 34, pp. 1457-1481. doi:10.1017/S0144686X13000214

Shaw, M. E. \& Westwood, M. J. (2002). Transformation in life stories: The Canadian war veterans life review project. In J. D. Webster \& B. K. Height (Eds.), Critical advances in reminiscence work: From theory to application (pp. 257-274). Springer Publishing Co: New York.

Spiro, A., III. and Settersten, R. A., Jr. (2012), "Long-term implications of military service for laterlife health and well-being". Research in Human Development, Vol. 9, pp. 183-190. doi:

$10.1080 / 15427609.2012 .705551$

The Royal British Legion (2014), A UK Household Survey of the Ex-service Community. Retrieved from: https://www.britishlegion.org.uk/media/2275/2014householdsurveyreport.pdf

Wong, P. T. and Watt, L. M. (1991), "What types of reminiscence are associated with successful aging?” Psychology and Aging, Vol. 6, pp., 272-279. doi:10.1037/0882-7974.6.2.272

Yang, M. S. and Burr, J. A. (2015), “Combat exposure, social relationships, and subjective well-being among middle-aged and older veterans", Aging \& Mental Health, doi:10.1080/13607863.2015.1033679 